\title{
The use of enzymatic hydrolyzate of Chlorophytum comosum with experimental toxic liver damage in rats
}

\author{
Areshidze David ${ }^{1}$, Timchenko Luydmila ${ }^{2}$, Kozlova Maria ${ }^{1}$ \\ ${ }^{1}$ Center of Cell Biology and Applied Biotechnology, Moscow State Regional University, Moscow, Russian federation \\ ${ }^{2}$ Institute of the living systems of the North Caucasus Federal University, Stavropol, Russian federation
}

Email address:

Nihilist78@mail.ru(A. David)

\section{To cite this article:}

Areshidze David, Timchenko Luydmila, Kozlova Maria. The Use of Enzymatic Hydrolyzate of Chlorophytum Comosum with Experimental Toxic Liver Damage in Rats. American Journal of Biomedical and Life Sciences. Vol. 1, No. 1, 2013, pp. 32-36. doi: 10.11648/j.ajbls.20130101.16

\begin{abstract}
Investigation of the influence of the enzymatic hydrolyzate of Chlorophytum comosumthe first on the liver of rats at its toxic damage showed that the substrate has expressed a pronounced hepatoprotective effect. Under its influence in the rat liver morphological changes induced by $\mathrm{CCl}_{4}$ are much less pronounced than in the controls. There are also less significant deviations from normal levels of ALT, AST and bilirubin. Information analysis of the state of the organ indicates that the level of adaptation and regeneration opportunities of the liver of rats treated with an enzymatic hydrolyzate of Chlorophytum comosum is significantly higher than that of the liver of rats with experimental toxic liver damage without the use of tested substrate.
\end{abstract}

Keywords: Liver, Hydrolizate, Hepatocyte, Chlorophytum Comosum

\section{Introduction}

In modern scientific literature there are few reports about the healing properties the plant Chlorophytum comosum. It is shown that the leaves of the plants have a high sorption characteristics with respect to formaldehyde, carbon monoxide, benzene, trichlorethylene, phenols and other compounds [1,2]. By chemical analysis of the enzymatic hydrolyzate of Chlorofitum comosum in its composition was found DL - ornithine monohydrochloride having disintoxicational and hepatoprotective action [5,6,7,8,9.10].

These facts allow us to consider this hydrolyzate as a biologically active substance having hepatoprotective properties, which allows authors to keep focused on the study of the effect of the hydrolyzateon a regenerative potential of the mammalian liver. To test the hypothesis about the effectiveness of bio-stimulation, we carried out a study which purpose was to examine the rate of liver damage while taking $\mathrm{CCl}_{4}$ and enzymatic hydrolyzate of Chlorophytum comosum.

\section{Materials and Methods}

In the study of the effectiveness of the influence of biologically active substances at the liver at different periods of ontogeny we have used 240 Wistar albino rats at the age ofthree months:

- intact animals;

- animals inhaled by carbon tetrachloride to $2 \mathrm{~min}$. per day for 6 days (control group);

- animals inhaled by carbon tetrachloride to $2 \mathrm{~min}$ a day for 6 days, but at the same time treated with drinking enzymatic hydrolyzate of Chlorophytum comosum at a dose of $0.6 \mathrm{mg}$ per $100 \mathrm{~g}$ of body weight (experimental group).

All procedures were carried out in compliance with the EC Directive 86/609/EEC and with the Russian law regulating experiments on animals.

The choice of carbon tetrachloride $\left(\mathrm{CCl}_{4}\right)$ as an agent acting on the liver, due to the fact that this substance is a direct liver poison, widely used in experimental medicine and biology. The choice of the liver-toxic exposure is determined by the fact that the use of carbon tetrachloride according this scheme provides the appearance and development of reversible changes in liver at tissue and organ levels.

All of the studied organs were collected after euthanasia of animals under ether anesthesia. After fixation of the material with $10 \%$ neutral buffered formalin, for a portion of organs was done the conducting through alcohols of the 
ascending density by the usual method,with the subsequent filling in paraffin. In conducting research of paraffinembedded organs, were prepared serial sections of 5-6 microns.

Hematoxylin-eosin staining was performed by the standard technique. Stained sections were embedded in balsam.

To detect apoptotic cells, semi-thin sections were stained with methylene blue-azure II with afterstain by fuchsin. Apoptotic index was calculated by the formula [8]:

$$
\mathrm{AI}=\mathrm{N}_{\mathrm{a}} / \mathrm{N} \text {, }
$$

where $\mathrm{N}_{\mathrm{a}}$ - the number of apoptotic cells; $\mathrm{N}$ - total number of cells in the studied population.

The mitotic index was determined by the formula:

$$
\mathrm{MI}=\mathrm{N}_{\mathrm{m}} / \mathrm{N} \text {, }
$$

where $\mathrm{N}_{\mathrm{m}}$ - number of mitosis; $\mathrm{N}$ - total number of cells in the studied population.

Necrotizing index was calculated by the formula:

$$
\mathrm{NI}=\mathrm{N}_{\mathrm{n}} / \mathrm{N}
$$

Where $\mathrm{N}_{\mathrm{n}}$ - number of necrotic cells; $\mathrm{N}$ - total number of cells in the test population.

To assess the degree of liver damage we also determined the following parameters: bilirubin, ALT, and AST levels in blood plasma.

Morphometric parameters of nuclei were measured by image analyzer "Videotest". Then we carried out a breakdown of the aggregate into classes, and then conducted a study of the entropy of the system of the liver.

To determine the information status at focal lesions of the liver, pieces of tissue were taken from the least altered areas on the border with macroscopically distinct lesions. In case of visual homogeneity of organ, material was taken from any part of it. Based on the concept of information in a tissue system as the displaying of the diversity of morphology and function of the process, for assessing the information status of organs and tissues have been proposed and tested the such indicators - information morphological capacity $\left(\mathrm{H}_{\max }\right)$, information morphological entropy $(\mathrm{H})$, information morphological organization $(\mathrm{S})$, the relative morphological entropy $(\mathrm{h})$ and redundancy $(\mathrm{R})$ [3]. In this case, the baseline characteristics, which were used to calculate these parameters, can vary widely (the linear dimensions of the structures, their number, etc.). In our study was defined the volume of the nuclei of hepatocytes.

Information morphological capacity $\mathrm{H}_{\max }$, which means the maximum structural diversity, calculated by formula [3]:

$$
\mathrm{H}_{\max }=\log _{2} \mathrm{n},
$$

where $\mathrm{n}$ - number of classes.

Next, we made the calculation of the real structural diversity $\mathrm{H}$. Real structural diversity is the parameter that clearly illustrates the degree of determinism of morphofunctional system in time and space [3].The calculation was made using the formula:

$$
\mathrm{H}=-\Sigma \mathrm{P}_{\mathrm{i}} \log _{2} \mathrm{P}_{\mathrm{i}},
$$

where $\Sigma \mathrm{P}_{\mathrm{i}}$ is the sum of probabilities of stay of the measured parameter of cells in a one of existing classes; $\log _{2} \mathrm{P}_{\mathrm{i}}$ logarithm of the probability of staying in one of the possible classes. In this case, the value of $\mathrm{P}_{\mathrm{i}}$ is defined as the classical probability [3].

Knowing the maximum and actual structural diversity, we can calculate the organization of the system (S), the difference between the maximum possible and the real structural diversity (implemented structural diversity). This parameter, in our opinion, displays the state of the system adaptability to date. To determine the value of this parameter is used the formula [3]:

$$
\mathrm{S}=\mathrm{H}_{\max }-\mathrm{H} \text {. }
$$

It is necessary to consider that when $\mathrm{H}=\mathrm{H}_{\max }$, the system is deterministic, but such relation to the vast majority of permissible is possible only in theory. Then we determined the coefficient of relative entropy of the system, or (the coefficient of compression of information) $h$ by formula[3]:

$$
\mathrm{h}=\mathrm{H} / \mathrm{H}_{\max } \text {. }
$$

High levels of relative morphological entropy provide an evidence of the disorder of the system and significantly reducing of its structural integrity [3].

The coefficient of the relative organization of the system (redundancy factor) $\mathrm{R}$ is given by [3]:

$$
\mathrm{R}=\left(\mathrm{S} / \mathrm{H}_{\max }\right) \times 100 \% .
$$

With these data, the researcher has the opportunity to calculate the equivocation of the system (the value of reliability) $\boldsymbol{e}[3]$ :

$$
\boldsymbol{e}=\left(\mathrm{H}_{\mathrm{p}}-\mathrm{H}_{\mathrm{n}}\right) / \mathrm{H}_{\max },
$$

where $H_{n}$ - real structural diversity in normal, $H_{p}$ - real structural diversity in pathology.

The statistical difference determined using repeated measures analysis of variance orpaired Student t-tests. A p value of $<0.05$ was considered statistically significant.

\section{Results and Discussion}

At the pathomorphologic examination of the liver of rats inhaled by carbon tetrachloride it was found by us that the organs of animals had a red color, sometimes with yellow or gray tint. About $20 \%$ of rat livers were spotty. The organ is loose, easily torn, bleeds at the cut. The histological study noted a pronounced diskomplexationof hepatic beams. Hepatocytes are swollen and their cytoplasm is cloudy, the boundaries of the cells are not clear; the nuclei are also swollen, bright, with blurred outlines. In hepatocytes 
clearly observed transparent vacuoles. When stained with Sudan-III in $65 \%$ of the cases in the vacuoles of hepatocytes revealed lipids. In rat liver hepatocytes detached state granular dystrophy. The vessels of the liver in different parts of the cut are unevenly expanded and filled with blood, in the field of triads there are signs of mild perivascular mesenchymal reaction (Fig. 1).

Blood vessels (central vein capillaries) in the liver are extended (hyperemia of blood vessels); the permeability of the walls of the vessels for blood cells is increased, marked by focal hemorrhage. Among the cells it is a large number of white blood cells, the macrophages. In hepatocytes it is a large number of vacuoles, including lipid, as evidenced by coloring with Sudan - III. Some cells are very large and represent in fact a continuous vacuole. In $70 \%$ of cases were showed multiple foci of necrosis in different sizes, in which the structural elements of the individual cells are not rendered, and the liver tissue is a homogeneous structureless mass. In $30 \%$ of cases are observed extensive necrosis.

The observed changes indicate the development of typical toxic liver diseaseat animal subgroups. However, at some rats were established characteristic of the micro-focal centers of inflammation and alteration. A significant proportion of rats have an expressed picture of acute toxic hepatitis with high intensity of tissue damage (hepatitis alterative). Some animals have severe steatosis with defined necrotic component.

The inhalation by $\mathrm{CCl}_{4}$ with the simultaneous use of the hydrolyzate of Chlorophytum comosum observed, that pathological changesin the liver are much less severity. A few pockets of malnutrition alternate with areas represented withtwo-nuclear and intact hepatocytes (signs of recovery) or hepatocytes which are able to start-up phase of granular dystrophy. Fatty degeneration occurs in 15\%. Also, expressivenessof hepatocyte necrosisis substantially less. It is noted the absence of focal hemorrhages, capillaries are moderately bloodshot, and there are no signs of swelling, and reduces the permeability of vessels which is registered in the group without the use of the hydrolyzate. Vessels in the triads are moderately dilated. In this case, in $28 \%$ of hepatocytes marked small vacuoles (Fig.2).

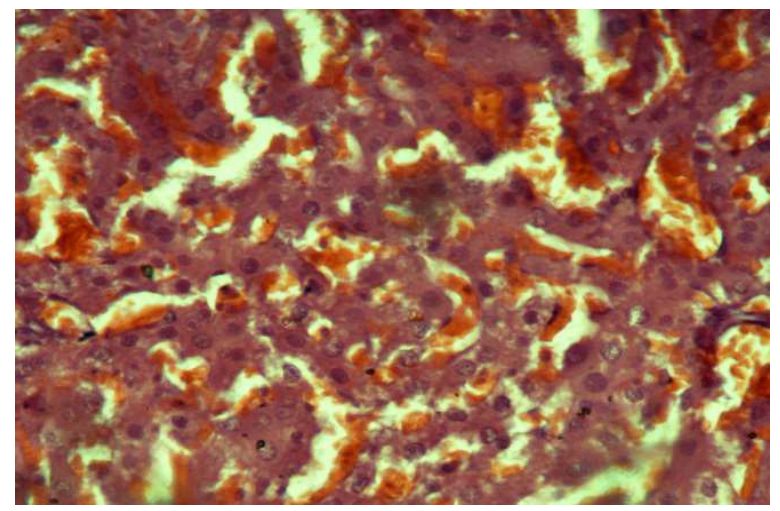

Fig 1. Ratliverof the control groupafterCCl $\mathrm{C}_{4}$ impact.HE $\times 200$.
For the liver of intact rats we found the MI equal to 5.35 $\pm 0.34 \%, \mathrm{AI}-1.55 \pm 0.26 \%$, and NI was $0.6 \pm 0.1 \%$. The value of MI in the liver of animals of the control group was $1.90 \pm 0.19 \%$, AI $-1.5 \pm 0.17 \%$ NI $-8.9 \pm 0.31 \%$. Application of enzymatic hydrolyzate of Chlorophytum comosum in experimental toxic injury of the liver leads to the MI of $4.7 \pm 0.21 \%, \mathrm{AI}-2.8 \pm 0.16 \%$, NI $-4.3 \pm 0.18 \%$. (Fig. 4).

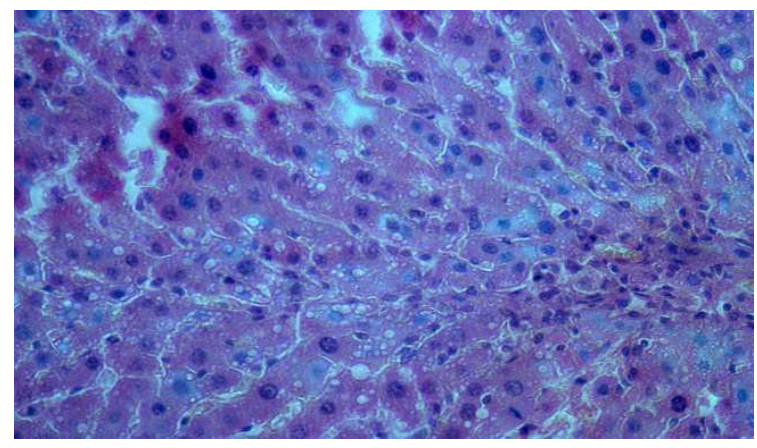

Fig 2. Ratliverof the experimental group. $H E \times 400$.

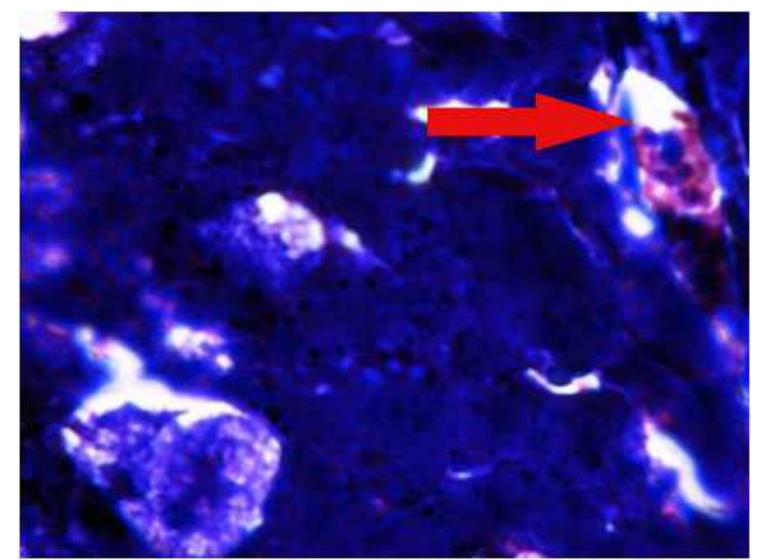

Fig 3. Apoptosisin the liverof rats withexperimental toxicinjury. The arrow shows thehepatocytewithformedapoptoticbodies. Methylene blue-azure II with afterstain by fuchsin, $\times 400$

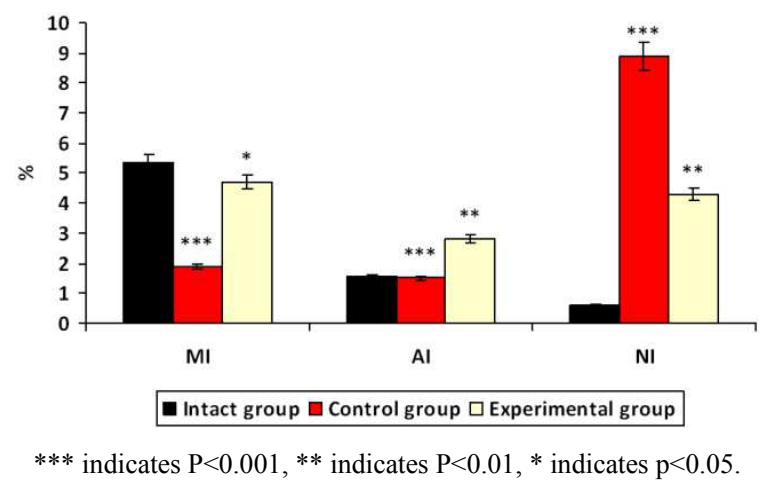

Fig 4. The value of MI, AI and NI in the liver of rats.

ALT levels in the blood of rats of the intact group was $1,66 \pm 0,09 \mathrm{mmol} / \mathrm{l}$, AST level was equal $1.4 \pm 0.01 \mathrm{mmol} / \mathrm{l}$. Application of hydrolyzate of Chlorophytum comosum in toxic liver damage leads to a substantial reduction of ALT $(2,03 \pm 0.1 \mathrm{mmol} / \mathrm{l}$ in the control vs $1.78 \pm 0.1 \mathrm{mmol} / \mathrm{l}$ in 
the blood of rats treated with the hydrolyzate) and AST $(1.94 \pm 0.06 \mathrm{mmol} / 1$ in the control vs $1.40 \pm 0.10 \mathrm{mmol} / \mathrm{l}$ in the blood of rats treated with the hydrolyzate). Bilirubin in blood of intact rats was $5.91 \pm 0.17 \mathrm{mmol} / \mathrm{l}$, bilirubin content in the blood of the experimental group of animals decreased to $6.88 \pm 0.12 \mathrm{mmol} / \mathrm{l}$ at $12.03 \pm 0.1 \mathrm{mmol} / \mathrm{l}$ in the control (Fig. 5).

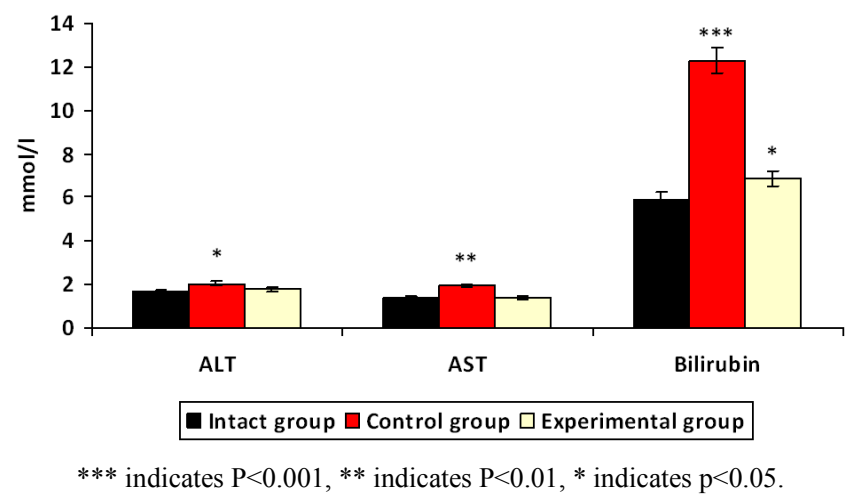

Figure 5. The value of $H, S$ and $h$ in the liver of rats.

The liver of rats of the intact group at the age of three months was characterized by $\mathrm{H}$ equal to $2.627 \pm 0.027$ bits, $\mathrm{S}$ amounted to $0.6926 \pm 0.027 \mathrm{bits}, \mathrm{h}$ is equal to $0.7914 \pm$ 0.008 bit, $\mathrm{R}$ amounted to $20.86 \pm 0.83 \%$ (Fig. 6,7).

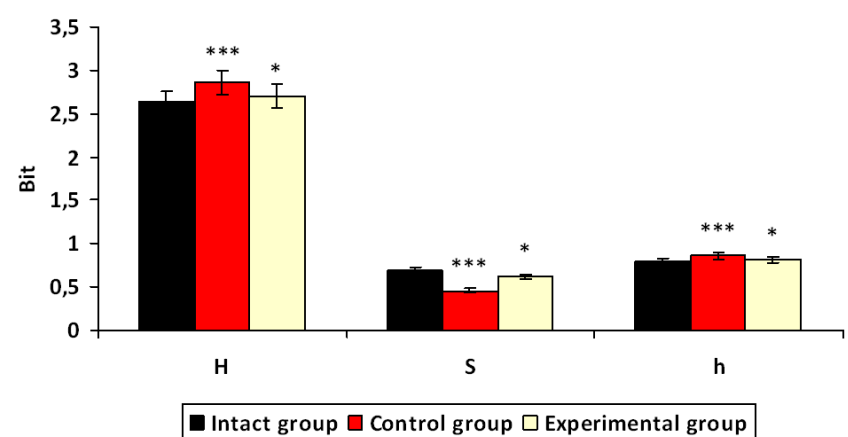

$* * *$ indicates $\mathrm{P}<0.001$, ** indicates $\mathrm{P}<0.01$, * indicates $\mathrm{p}<0.05$.

Figure 6. The value of $H, S$ and $h$ in the liver of rats.

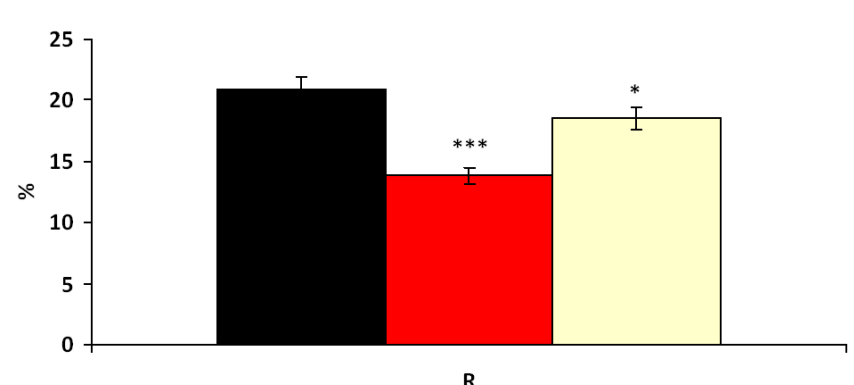

[ Intact group $\square$ Control group $\square$ Experimental group

*** indicates $\mathrm{P}<0.001, * *$ indicates $\mathrm{P}<0.01$, * indicates $\mathrm{p}<0.05$.

Figure 7. The value of $R$ in the liver of rats.

Information indicators of liver of rats being exposed to $\mathrm{CCl}_{4}$ differ significantly from the age norm. Thus, $\mathrm{H}$ is
$2.862 \pm 0.023$ bits, $\mathrm{S}$ is equal to $0.458 \pm 0.023 \mathrm{bits}, \mathrm{h}-$ $0.8620 \pm 0.007$ bits, $\mathrm{R}-13.8 \pm 0.71 \%, \boldsymbol{e}$ amounted to 0,235 $\pm 0,012$ bit.

The liver of rats treated with the enzymatic hydrolyzate in parallel with inhalation by $\mathrm{CCl}_{4}$ is characterized by information parameters differ from the liver of rats only inhaled by carbon tetrachloride. This difference from the liver of rats of control group was unreliable. $\mathrm{H}$ was $2.704 \pm$ 0.026 bits, $\mathrm{S}$ was $0.6156 \pm 0.026$ bits, $\mathrm{h}-0.8146 \pm 0.007$ bits, $\mathrm{R}$ is equal to $18.54 \pm 0.079 \%, \boldsymbol{e}$ was $0.091 \pm 0.004 \mathrm{bit}$.

\section{Conclusions}

Studies suggest that enzymatic hydrolyzateof Chlorophytum comosum has significant hepatoprotective properties, reduces the intensity of the inflammatory process. It was observed a pronounced positive effect of the hydrolyzate on liver regeneration, as evidenced by differences in the mitotic, necrotic, apoptotic index and the proliferation rate in the experimental groups. The liver of rats treated with an enzymatic hydrolyzate of Chlorofitum comosum at toxic damage, based on analysis of the information state of organ, is characterized by a higher level of adaptation and regenerative capacity than the liver of rats of the first experimental group.

\section{Acknowledgments}

Financial support for this study was provided by Moscow regional state university.

\section{References}

[1] T.H.Arnoldand B.C. de Wet,"Plants of southern Africa: names and distribution", Memoirs of the Botanical Surveys of South Africa, 1993, vol. 62, pp.968.

[2] S.E. Afton, B. Catron and J.A. Caruso,"Elucidating the selenium and arsenic metabolic pathways following exposure to the non-hyperaccumulatingChlorophytum comosum, spider plant", Journal of Experimental Botany 2009, vol. 60; 4, pp.1289-1297.

[3] G.G.Avtandilov 2008.Medical Morphometry [in Russian]. Moscow:Meditsina,. pp.298.

[4] M. Giese, U. Bauer-Doranth, S.Langebartels, and H. Sandermann" Detoxification of Formaldehyde by the Spider Plant (Chlorophytum comosum L.) and by Soybean (Glycine max L.) Cell-Suspension Cultures", Plant Physiology1994, vol. 4, pp. 1301-1309.

[5] A.J.Haagen-Smit, E.F. Darley, M.Zaitlin, H. Hull and W.Noble "Investigation on injury to plants from air pollution in the Los Angeles area", Plant Physiology, 1952; vol. 27, pp. 18-34.

[6] C.P. Kala, B.S.Dhyani and B.S.Sajwan. "Developing the medicinal plants sector in northern India: challenges and opportunities", Journal of Ethnobiology and Ethnomedicine. 2006,vol. 6, pp. 32-38. 
[7] M.D. Logsdon, Jr. Meyn,and P.C.Besa. "Apoptosis and the Bcl-2 gene family: patterns of expression and prognostic value in stage I and II follicular center lymphoma?",Int $\mathrm{J}$ RadiatOncolBiolPhys 1999,vol.44, pp. 19-29.

[8] H. Matsushita, H.Kuwabara, H. Matsushita, S. Ishikawa and M. Mochizuki. "Apoptosis Induced in Human Cell Lines by a Butanol Extract from Chlorophytum comosum", Roots Journal of Health Science, 2005,vol. 51, pp. 341-345.
[9] M. Thakur, S. Bhangava and V. Dixit "Immunomodulatory Activity of Chlorophytum borivilianum", Sant. Evid Based Complement Alternative Medicine, 2007, vol. 4, pp. 419423.

[10] R.A. Wood, R. Orwell, M.D. Burchett, J. Tarran and S.K. Brown. "Absorption of organic compounds in indoor air by commonly used indoor plants", Proceedings of Healthy Buildings,2000, vol. 2, pp. 125-130. 